\title{
Fatores Determinantes da Estrutura de Capital das Maiores Empresas do Sul do Brasil em 2007
}

\author{
Determinants of Capital Structure of the Largest Companies in Southern Brazil \\ in 2007
}

\author{
Flaviano Costa \\ Mestrando em Contabilidade pela UFPR \\ Ana Paula Mussi Szabo Cherobim \\ Doutora em Administração pela USP \\ Professora Adjunta da UFPR
}

\author{
Ana Paula Capuano da Cruz \\ Mestranda em Contabilidade pela UFPR \\ Márcia Maria dos Santos Bortolocci Espejo \\ Doutora e Controladoria e Contabilidade pela USP \\ Coordenadora do Programa de Mestrado da UFPR
}

\begin{abstract}
Resumo
O presente estudo apresenta uma investigação acerca dos fatores determinantes da estrutura de capital das maiores empresas do Sul do Brasil no ano de 2007. O estudo que originou esse artigo testa e analisa as variáveis apontadas na teoria financeira como fatores que podem determinar a estrutura de capital. A amostra está constituída pelas maiores empresas do Sul do Brasil no ano de 2007, classificadas de acordo com as receitas auferidas, catalogadas pela Revista Exame - edição 2008. As variáveis eleitas para esse fim foram a liquidez geral, a rentabilidade, o tamanho da empresa, e o EBITDA (earnings before interests, taxes, depreciation and amortization). A abordagem metodológica é quantitativa, por meio da aplicação de regressão múltipla para explicar a influência das variáveis selecionadas na estrutura de capitais das empresas pesquisadas. Os resultados obtidos indicaram que os fatores: índice de liquidez geral, rentabilidade e EBITDA são fatores relevantes que influenciam o grau de endividamento das organizações selecionadas para análise, enquanto o tamanho da empresa não teve significância estatística suficiente para demonstrar tal relação.

Palavras chave: Estrutura de Capital, Finanças Corporativas, Regressão Múltipla.
\end{abstract}

\begin{abstract}
This study presents a research on the determinants of capital structure of the largest companies in southern Brazil in 2007. The study that resulted in this article tests and analyzes the variables defined in financial theory as factors that may determine the capital structure. The sample is comprised of the largest companies in southern Brazil in 2007, ranked according to revenues, cataloged by Exame Magazine - edition 2008. The variables that were chosen for this purpose are: the general liquidity, profitability, company size, and EBITDA (earnings before interests, taxes, depreciation and amortization). The approach is quantitative, using multiple regression analysis to explain the influence of selected variables in the capital structure of companies surveyed. The results indicated that the following factors: general index of liquidity, profitability and EBITDA are factors that influence the degree of indebtedness of the organizations concerned for analyze, as the size of the company was not statistically significant to show that relation.
\end{abstract}

Key-words: Capital Structure, Corporate Finance, Multiple Regression

\section{INTRODUÇÃO}

Os fatores determinantes das fontes de financiamento de uma empresa constantemente são foco de pesquisas em Teoria das Finanças porque não há consenso quanto à existência de uma estrutura ótima de capital. Muitas pesquisas empíricas nacionais e internacionais têm sido feitas com o intuito de determinar as variáveis que podem influenciar a estrutura de capitais de uma organização (TOY et al, 1974; FERRI e JONES, 1979; BRADLEY, JARREL 
e KIM, 1984; TITMAN e WESSELS, 1988; RAJAN e ZINGALES, 1995; BRITO, CORRAR e BATISTELLA, 2007; NAKAMURA et al, 2007). Corroborando com essa visão, Souza, Funchal e Baptista (2009) expõe que muitos pesquisadores têm associado a estrutura de capitais das empresas com suas características específicas e também com as do país nas quais estão estabelecidas.

Modigliani e Miller (1958) expuseram que a proporção de capital de terceiros em relação ao capital próprio (endividamento) utilizado por uma empresa é completamente irrelevante para a determinação de seu valor de mercado, ou seja, essa teoria considera que a dívida não afeta o valor da empresa e ficou conhecida como Teoria da Irrelevância da Estrutura de Capital. Contrapondo-se a essa teoria surgiram outras como a do Pecking Order e do Trade-Off. Para Nakamura et al (2007, p.73), "[...] a suposta existência de um nível ótimo de endividamento das empresas não exclui a possibilidade de que possa haver outras razões, teóricas ou práticas, que expliquem a forma como as empresas definem seu composto de capital $[\ldots] "$..

Como conseqüência dos pressupostos supracitados, a questão que orienta o presente estudo é a seguinte: a rentabilidade, o tamanho da empresa, a liquidez geral e o EBITDA (earnings before interests, taxes, depreciation and amortization), são determinantes da estrutura de capital das maiores empresas do Sul do Brasil escolhidas pela Revista Exame no ano de 2007? O estudo que originou esse artigo testa e analisa as variáveis apontadas na teoria financeira como fatores que podem determinar a estrutura de capital. A amostra está constituída pelas maiores empresas do Sul do Brasil no ano citado.

Este estudo justifica-se também pela diferença existente entre a realidade empresarial brasileira e o ambiente onde as teorias de estrutura de capital foram desenvolvidas. Dentre as características que motivam a pesquisa de estruturas de capital no Brasil estão: [1] mercado de capitais restrito; [2] elevadas taxas de juros que tornam o custo de capital elevado sinalizando níveis baixos de endividamento das empresas brasileiras; [3] o custo de capital de terceiros não é função apenas do risco do tomador, mas também da natureza da fonte de financiamento. No Brasil há um crescimento de estudos nessa temática (SANTOS, 2006; NAKAMURA et al, 2007; BRITO, CORRAR e BATISTELLA, 2007).

Salienta-se que não se tem a pretensão de esgotar o assunto proposto para discussão ou tentar explicar qual deve ser a melhor estrutura de capital para as empresas estudadas e nem tampouco potencializar as variáveis utilizadas nesse estudo como sendo as de maior relevância em detrimento de outras que possam ser mais explicativas. Desse modo, esta investigação categoriza-se, metodologicamente como um artigo que utiliza métodos quantitativos por meio de regressão múltipla para explicar a influência das variáveis selecionadas na estrutura de capitais das empresas pesquisadas.

O presente artigo está estruturado em mais três seções além dessa. Na segunda seção desenvolve-se o referencial teórico que respalda o estudo em questão. Na terceira seção são apresentados os procedimentos metodológicos utilizados nessa investigação. Na quarta seção são analisados e discutidos os resultados obtidos por meio da aplicação de métodos estatísticos e por fim, na última seção, são expostas as considerações finais.

\section{REFERENCIAL TEÓRICO}

No estudo de estrutura de capital há duas grandes correntes teóricas sobre o assunto: a tradicionalista, representada por Durand (1952) e a da irrelevância de capitais, concebida por Modigliani e Miller (1958). A teoria tradicional sugere que a estrutura de capital influencia o valor da empresa e contrapondo-se a essa visão a teoria da irrelevância de capitais propõe que a escolha das fontes de financiamento não influencia o valor da empresa. 


\subsection{TEORIA DA IRRELEVÂNCIA DA ESTRUTURA DE CAPITAL}

A teoria da irrelevância da estrutura de capital proposta por Modigliani e Miller (1958) mostra que o valor da empresa não é afetado por seu endividamento, permitindo que as decisões de investimento e de financiamento possam ser consideradas separadamente. As argumentações dos autores decorrem, inicialmente, de um estudo empírico que desencadeou o surgimento de inúmeras investigações acerca da temática de estrutura de capital. Ressalta-se que a primeira pesquisa realizada pelos autores (proposição I de MM), tinha como cenário um ambiente ideal, onde são desconsiderados os impostos, os custos de agência, os custos de transação e os custos de falência diretos ou indiretos. As contribuições advindas da pesquisa desenvolvida por Modigliani e Miller (1958) ficaram conhecidas como teoria MM, a qual, inicialmente, baseou-se no delineamento de três pressupostos básicos, amplamente tratados como proposições I, II e III, resumidas no Quadro 1.

\begin{tabular}{|c|c|c|}
\hline \multicolumn{3}{|c|}{ PROPOSIÇÕES DE M \& M } \\
\hline PROPOSIÇÃO I & PROPOSIÇÃO II & PROPOSIÇÃo III \\
\hline $\begin{array}{l}\text { A proporção de capital de terceiros } \\
\text { em relação ao capital próprio } \\
\text { utilizado por uma empresa é } \\
\text { completamente irrelevante para a } \\
\text { determinação de seu valor de } \\
\text { mercado. Assim, o valor da } \\
\text { empresa alavancada é igual ao da } \\
\text { empresa não alavancada. }\end{array}$ & $\begin{array}{l}\text { Qualquer aumento na alavancagem } \\
\text { financeira por meio de um maior } \\
\text { endividamento traduz-se num risco } \\
\text { maior para os acionistas da empresa } \\
\text { e, conseqüentemente, numa } \\
\text { majoração do custo do capital } \\
\text { próprio. }\end{array}$ & $\begin{array}{l}\text { O custo marginal do capital } \\
\text { para uma empresa é igual ao } \\
\text { custo médio de capital. Este é } \\
\text { igual à taxa de capitalização } \\
\text { para uma empresa não } \\
\text { alavancada na classe à qual } \\
\text { pertence. }\end{array}$ \\
\hline
\end{tabular}

Quadro 1: Proposições de Modigliani e Miller

Fonte: Adaptado de Famá, Barros, Silveira (2001); Ross, Westerfield, Jaffe (2007) e Cruz et al (2008)

Devido às diversas críticas feitas por outros pesquisadores, Modigliani e Miller (1963) refizeram a mesma pesquisa introduzindo as alíquotas de imposto de renda em seu teorema e chegaram à conclusão de que a irrelevância da dívida não ocorre em todas as circunstâncias; em vez disso, abre a possibilidade de que a dívida ainda possa ser irrelevante, apesar de suas vantagens tributárias.

\subsection{TEORIA DE TRADE-OFF}

Contrapondo-se à teoria de Modigliani e Miller surgiu a teoria de Trade-Off que tentou, por meio de investigações teóricas e empíricas, determinar o nível ótimo de estrutura de capital, pois, de acordo com a corrente tradicional, o custo da dívida continua estável até um determinado nível de endividamento, a partir do qual fica mais elevado em razão do risco falimentar. Em função disso, a empresa deveria se endividar até o ponto em que o custo de capital total atingisse um nível mínimo. Nesse caso, obter-se-ia a estrutura ótima de capital e a maximização do valor da empresa.

Titman e Wessels (1988) afirmam que várias teorias foram propostas para explicar o endividamento das empresas, e que a estrutura de capital depende dos custos e benefícios associados a esta dívida. Complementarmente, observam que os estudos empíricos são muito menores nessa área com relação às investigações teóricas, atribuindo esse fato a conceitos abstratos que não são diretamente observáveis. Corroborando com essas visões, o Quadro 2 apresenta algumas das vantagens e desvantagens que o endividamento representa na estrutura de capitais das empresas. 


\begin{tabular}{|c|c|}
\hline VANTAGENS DO ENDIVIDAMENTO & DESVANTAGENS DO ENDIVIDAMENTO \\
\hline 1. Benefícios em imposto de renda: & 1. Custo de falência: \\
\hline $\begin{array}{l}\text { Alíquotas de imposto de renda mais } \\
\text { elevadas } \rightarrow \text { benefícios em imposto de renda } \\
\text { mais elevados. } \\
\text { 2. Disciplina agregada: }\end{array}$ & $\begin{array}{l}\text { Risco setorial mais elevado } \rightarrow \text { custo mais elevado. } \\
\text { 2. Custo de agência: } \\
\text { Quanto maior a separação entre acionistas e financiadores } \rightarrow \\
\text { mais alto o custo. }\end{array}$ \\
\hline $\begin{array}{l}\text { Quanto maior a separação entre } \\
\text { administradores e acionistas } \rightarrow \text { maior o } \\
\text { benefício. }\end{array}$ & $\begin{array}{l}\text { 3. Perda de flexibilidade de financiamento futura: } \\
\text { Quanto maior a incerteza a respeito das necessidades de } \\
\text { financiamento } \rightarrow \text { mais alto o custo. }\end{array}$ \\
\hline
\end{tabular}

Miller (1977) estudou a existência dos custos de falência, demonstrando que quanto mais a empresa se endivida, maior é a exigência de disponibilidades de recursos para pagamento de juros e para o pagamento das parcelas da dívida principal, o que pode aumentar a probabilidade de falência da organização. Portanto, a utilização de capitais de terceiros num nível em que o custo do capital se torna muito elevado implica anulação do benefício representado pela economia de impostos, aumentando assim, a vulnerabilidade da empresa ao processo falimentar.

Nesse sentido, a Teoria de Trade-Off sugere a existência de um nível ótimo de endividamento; ocasião em que a instituição beneficia-se com a economia de impostos e com administradores disciplinados, não apresentando custos de agência e de falência, ou ainda perda de flexibilidade de financiamentos futuros que anulem ou comprometam as vantagens da utilização de capitais de terceiros.

\subsection{TEORIA DE PECKING ORDER}

Jensen e Meckling (1976) investigaram os custos de agência. Tal teoria trata do relacionamento entre agentes nas trocas econômicas, onde um ator denominado principal tem poder sobre o comportamento de outro ator, designado agente, em seu favor, e o bem-estar do principal sofre influência das decisões do agente. Portanto, o executivo pode realizar investimentos cuja rentabilidade é duvidosa com o objetivo de aumentar o seu poder em detrimento a distribuir dividendos aos acionistas, como seria recomendado na falta de investimentos atraentes.

Outro conflito de agência existente na organização é entre os acionistas e os portadores de títulos, que se desenvolve nas diferenças de direitos sobre os fluxos de caixa de ambos. Segundo Damodaran (2002), os portadores de títulos geralmente exercem primeiro seus direitos sobre os fluxos de caixa, mas recebem montantes fixos, supondo que a empresa possua recursos para honrar suas dívidas e; os acionistas exercem seus direitos sobre os fluxos de caixa residuais e podem decretar um processo falimentar se não conseguir atender às obrigações que possui.

Destarte, o aumento da alavancagem, especialmente se este for expressivo a ponto de afetar a capacidade de pagamento da empresa ou se os portadores de títulos estiverem desprotegidos, pode causar custos de agência. Tais custos são decorrentes da assimetria informacional, estudada por Myers e Majluf (1984). Esse fato ocorre quando alguns agentes econômicos têm mais informações que outros, e assim, possuem um privilégio para tomar as melhores decisões. Por meio desses estudos, Myers (1984) propôs a teoria do Pecking Order, que considera a existência de uma hierarquia nas fontes de financiamento, ou seja, a obtenção de recursos obedece a uma ordem de preferência. O Quadro 3 demonstra a ordem de preferência da Teoria Pecking Order 


\begin{tabular}{|c|l|}
\hline ORDEM & \multicolumn{1}{|c|}{ FORMA DE OBTENÇÃO DOS RECURSOS } \\
\hline $1^{\text {o }}$ & Financiamento interno - retenção dos lucros. \\
\hline $2^{\text {o }}$ & $\begin{array}{l}\text { Financiamento externo - dívidas (títulos mais seguros). } \\
\text { Financiamento externo - novas ações (ordinárias e preferenciais). }\end{array}$ \\
$3^{\text {o }}$ & Quadro 3: Ordem de Preferência da Teoria de Pecking Order. \\
& Fonte: Adaptado de Myers (1984)
\end{tabular}

Nakamura et al (2007, p. 73), reportando-se à Teoria do Pecking Order, afirmam que "[...] mesmo que os administradores sigam tal hierarquia não fica invalidada a idéia de um nível ótimo de endividamento na linha proposta pela denominada teoria do Trade-off [...]".

\section{METODOLOGIA}

De acordo com Cooper e Schindler (2003) a presente pesquisa pode ser categorizada da seguinte forma: estudo formal, ex post facto, causal, transversal e estatístico. Para melhor responder à questão de pesquisa proposta, foram desenvolvidas e testadas quatro hipóteses envolvendo as variáveis que podem influenciar e determinar a estrutura de capitais das empresas investigadas. As hipóteses foram baseadas nas teorias orientadoras relacionadas no referencial teórico e em estudos empíricos de outros autores.

\subsection{HIPÓTESES DE PESQUISA}

As hipóteses dessa pesquisa envolvem a exploração de quatro fatores como possíveis determinantes da estrutura de endividamento das empresas analisadas, são eles: liquidez, rentabilidade, tamanho da empresa e EBITDA, conforme Quadro 4.

\begin{tabular}{|c|c|c|}
\hline VARIÁVEL & TEORIA & HiPÓTESE \\
\hline Índice de Liquidez Geral & $\begin{array}{l}\text { Esse índice indica a capacidade de pagamento da empresa } \\
\text { tanto a curto como no longo prazo. Se esse índice for } \\
\text { menor que 1, significa que para manter a solvência, } \\
\text { dependerá de lucros futuros, renegociação das dívidas ou } \\
\text { venda de ativos. Portanto, quanto maior for o } \\
\text { endividamento total da empresa, geralmente, menor será } \\
\text { sua liquidez geral (ASSAF NETO, 2006). }\end{array}$ & $\begin{array}{l}\text { Hipótese 1: há uma relação } \\
\text { negativa entre a liquidez geral } \\
\text { e endividamento. }\end{array}$ \\
\hline Rentabilidade & $\begin{array}{l}\text { Na teoria do Pecking Order, há uma hierarquia nas fontes } \\
\text { de financiamento das empresas, que preferem financiar } \\
\text { seus investimentos por meio da retenção de lucros, em } \\
\text { detrimento a recursos de terceiros e a origem de recursos } \\
\text { dos acionistas. Assim, a capacidade de geração de lucros } \\
\text { da empresa influenciaria sua estrutura de capital (MYERS, } \\
\text { 1984). }\end{array}$ & $\begin{array}{l}\text { Hipótese 2: há uma relação } \\
\text { negativa entre rentabilidade e } \\
\text { endividamento. }\end{array}$ \\
\hline Tamanho da Empresa & $\begin{array}{l}\text { Com relação aos custos de falência, observa-se que, } \\
\text { geralmente, empresas grandes, são mais diversificadas que } \\
\text { as pequenas, estando menos sujeitas às dificuldades } \\
\text { financeiras e possuindo custos de falências menores } \\
\text { (TITMAN e WESSELS, 1988). }\end{array}$ & $\begin{array}{l}\text { Hipótese 3: há uma relação } \\
\text { positiva entre o tamanho da } \\
\text { empresa e endividamento. }\end{array}$ \\
\hline EBITDA & $\begin{array}{l}\text { A empresa com retornos mais altos antes do imposto de } \\
\text { renda pode suportar um endividamento muito alto com } \\
\text { relação ao seu valor de mercado, já que os pagamentos de } \\
\text { dívida podem ser atendidos muito mais facilmente a partir } \\
\text { dos fluxos de caixa correntes (DAMODARAN, 2002). }\end{array}$ & $\begin{array}{l}\text { Hipótese 4: há uma relação } \\
\text { positiva entre os retornos antes } \\
\text { do imposto de renda } \\
\text { (EBITDA) e endividamento. }\end{array}$ \\
\hline
\end{tabular}

Quadro 4: Hipóteses da Pesquisa

Fonte: Adaptado de Brito, Corrar e Batistella (2007) 


\subsection{POPULAÇÃO E AMOSTRA}

A pesquisa é feita com base nas 100 (cem) maiores empresas do Sul do Brasil categorizadas pela Revista Exame, de acordo com a receita auferida por elas no ano de 2007. Das 100 empresas escolhidas, algumas não possuem informações referentes às variáveis selecionadas e, portanto, foram excluídas da amostra selecionada, perfazendo um total de 81 (oitenta e uma) empresas. Para melhor análise dos dados obtidos, foram considerados os efeitos inflacionários incidentes sobre a amostra em 2007.

\subsection{VARIÁVEIS}

As variáveis utilizadas neste estudo foram definidas com base nas hipóteses formuladas. A variável dependente é o endividamento contábil e representa a estrutura de capitais das empresas selecionadas na amostra. De acordo com a Revista Exame, esse indicador foi calculado somando-se o passivo circulante (PC) com o exigível de longo prazo (PELP), o resultado é mostrado em porcentagem, em relação ao ativo total ajustado e representa o total de capital de terceiros que financia os negócios da empresa. A variável dependente é calculada de acordo com o Quadro 5:

\begin{tabular}{|c|c|c|}
\hline $\begin{array}{c}\text { VARIÁVEL } \\
\text { Endividamento }\end{array}$ & $\begin{array}{c}\text { SIGLA } \\
\text { END }\end{array}$ & DEFINIÇão OPERACIONAL \\
(Passivo Circulante + Exigível a longo prazo) / Ativo total \\
\hline \\
Quadro 5: Variável dependente \\
Fonte: Elaborado pelos autores
\end{tabular}

As variáveis independentes deste estudo demonstram os fatores que podem determinar a estrutura de capital das empresas selecionadas. Como não foram encontradas na literatura regras rígidas para a operacionalização dessas variáveis, portanto, foram utilizadas como referência, pesquisas empíricas já realizadas nessa temática. As variáveis independentes são: rentabilidade (RENT), tamanho da empresa (TAEM), índice de liquidez geral (ILG) e EBITDA, calculados e operacionalizados de acordo com Quadro 6.

\begin{tabular}{|c|c|c|}
\hline VARIÁVEL & SIGLA & DEFINIÇÃO OPERACIONAL \\
\hline Índice de liquidez geral & ILG & $\begin{array}{l}\text { (Ativo Circulante }+ \text { Ativo Realizável a longo prazo) / (Passivo } \\
\text { Circulante }+ \text { Passivo Exigível a longo prazo) }\end{array}$ \\
\hline Rentabilidade & RENT & Lucro líquido ajustado / Patrimônio líquido ajustado \\
\hline Tamanho da empresa & TAEM & LN (logaritmo natural) da Receita de Vendas \\
\hline EBITDA & EBITDA & $\begin{array}{l}\text { Caixa gerado pelas operações da empresa - lucro antes de } \\
\text { descontar os juros, os impostos sobre o lucro, a depreciação e a } \\
\text { amortização. }\end{array}$ \\
\hline
\end{tabular}

\subsection{PROCEDIMENTOS ESTATÍSTICOS}

O procedimento estatístico utilizado é a Regressão Múltipla Linear, pelo método dos Mínimos Quadrados Ordinários (MQO). O modelo matemático utilizado aparece abaixo:

$$
\text { END }_{i}=\alpha+\beta_{1} \operatorname{RENT}_{i}+\beta_{2} \text { TAEM }_{i}+\beta_{3} I L G_{i}+\beta_{4} \text { EBITD }_{i}+\mu
$$

Onde: $E N D$ é o endividamento da empresa $i$ no ano de 2007; $\alpha$ é o intercepto da reta; $\beta$

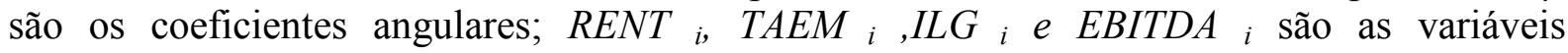
independentes da empresa $i$ no ano de 2007 e $\mu$ é o erro estocástico.

\subsection{VAlidação das Suposições Básicas do Modelo de Regressão MúltiPla}


Para que os testes estatísticos propostos no presente artigo sejam válidos, quatro pressupostos devem ser testados e aceitos: [1] a independência dos erros ou autocorrelação residual; [2] a homocedasticidade; [3] a normalidade dos resíduos e; [4] a multicolinearidade. O Quadro 7 demonstra a interpretação de cada um desses pressupostos.

\begin{tabular}{|c|c|}
\hline Pressuposto & INTERPRETAÇÃO \\
\hline $\begin{array}{l}\text { Independência dos erros ou } \\
\text { autocorrelação residual }\end{array}$ & $\begin{array}{l}\text { "[...] os resíduos }(\mathrm{u}) \text { devem ser distribuídos aleatoriamente em torno da reta de } \\
\text { regressão. Portanto, os resíduos não devem ser correlacionados uns com os } \\
\text { outros [...]" (CORRAR, THEÓPHILO e BERGMANN, 2004, p. 100). }\end{array}$ \\
\hline Homocedasticidade & $\begin{array}{l}\text { "[...] quando a variância dos termos de erro parece constante ao longo de um } \\
\text { domínio de variáveis preditoras, diz-se que os dados são homocedásticos [...]" } \\
\text { (HAIR JR. et al., 2005, p. 51). }\end{array}$ \\
\hline Normalidade dos resíduos & $\begin{array}{l}\text { "[...] grau em que a distribuição dos dados da amostra corresponde a uma } \\
\text { distribuição normal [...]" (HAIR JR. et al., 2005, p. 51). }\end{array}$ \\
\hline Multicolinearidade & $\begin{array}{l}\text { "[...] extensão em que uma variável pode ser explicada pelas outras variáveis } \\
\text { da análise. À medida que a multicolinearidade aumenta, fica mais complicada } \\
\text { a interpretação da variável estatística, uma vez que se torna mais difícil } \\
\text { verificar o efeito de qualquer variável, devido a suas inter-relações [...] (HAIR } \\
\text { JR. et al., 2005, p. 24). }\end{array}$ \\
\hline
\end{tabular}

Quadro 7: Interpretação dos Pressupostos Básicos de um Modelo de Regressão Fonte: Elaborado pelos autores

Cada um dos pressupostos mencionados no Quadro 6 apresentam uma ou mais técnicas estatísticas para serem testadas. Essa primeira análise é fundamental para as validações posteriores, pois a violação de qualquer uma dessas suposições compromete o modelo de regressão como um todo, favorecendo a formação de relações espúrias entre as variáveis e incorreções quando da análise empírica em comparação com as bases teóricas expostas.

\subsubsection{Independência dos Erros ou Autocorrelação Residual}

Como já mencionado anteriormente, esse pressuposto desvela que os resíduos não podem ser correlacionados entre si, portanto, se os erros seguirem um comportamento não aleatório, de modo a apresentarem uma tendência, essa suposição básica é violada. Para determinação da independência dos erros, utilizou-se o Teste de Durbin-Watson (DW), cujo qual, mede a correlação entre cada resíduo e o resíduo da observação imediatamente anterior. A Tabela 1 demonstra os resultados obtidos.

Tabela 1 - Teste de Durbin-Watson (DW)

\begin{tabular}{|c|c|c|c|}
\hline $\begin{array}{c}\text { TÉCNICA } \\
\text { ESTATÍSTICA } \\
\text { UTILIZADA }\end{array}$ & FóRMULA & $\begin{array}{l}\text { INTERVALO DE AUSÊNCIA DE } \\
\text { CORRELAÇÃO }\end{array}$ & $\begin{array}{c}\text { VALOR } \\
\text { ENCONTRADO PARA } \\
\text { O COEFICIENTE DW }\end{array}$ \\
\hline $\begin{array}{c}\text { Teste de } \\
\text { Durbin-Watson } \\
\text { (DW) }\end{array}$ & $\begin{array}{l}\quad \mathbf{D W}=\boldsymbol{\Sigma}\left(\mathbf{u}_{\mathrm{t}}-\mathbf{u}_{\mathrm{t}-1}\right)^{\mathbf{2}} / \boldsymbol{\Sigma} \mathbf{u}_{\mathbf{t}}{ }^{2} \\
\text { Onde: } \mathrm{u}_{\mathrm{t}} \text { é o resíduo no período } \\
\text { de tempo t e } \mathrm{u}_{\mathrm{t}-1} \text {, é o resíduo no } \\
\text { período de tempo t-1. }\end{array}$ & $1,748<$ Coeficiente DW $<2,2562$ & 1,9847 \\
\hline
\end{tabular}

Fonte: Elaborado pelos autores

Os limites críticos inferior e superior foram retirados da tabela de valores críticos da estatística de Durbin-Watson para um nível de significância de 5\%. O valor calculado de coeficiente DW é de 1,9847 e se encontra no intervalo de ausência de correlação, isto é, o 
pressuposto de independência dos erros não foi violado.

\subsubsection{Homocedasticidade}

Para testar o pressuposto da homocedasticidade utilizou-se o Teste de Breusch-PaganGodfrey (BPG). Esse teste consiste em encontrar o fator $\sigma^{2}$ dividindo-se o valor do SQR (somatório dos quadrados da regressão) pelo número de observações. Tal coeficiente serve como denominador para a razão que determina a construção da variável $\rho\left(\rho=\operatorname{resíduos}^{2} / \sigma^{2}\right)$. Obtidas essas variáveis, calcula-se novamente a regressão, porém, relacionando os valores de $x$ com os valores de $\rho$, e por fim, divide-se o resultado do SQR desta nova regressão por 2 e encontra-se o valor de $\theta$ que é comparado ao valor tabelado da distribuição de qui-quadrado (GUJARATI, 2006). A Tabela 2 mostra os valores encontrados nesse teste.

Tabela 2 - Teste de Breusch-Pagan-Godfrey (BPG)

\begin{tabular}{c|c|c}
\hline $\begin{array}{c}\text { TÉCNICA ESTATísTICA } \\
\text { UTILIZADA }\end{array}$ & $\begin{array}{c}\text { VALOR DA DISTRIBUIÇÃO DE } \\
\text { QUI-QUADRADO }\end{array}$ & VALOR CALCULADO DE $\boldsymbol{\theta}$ \\
\hline $\begin{array}{c}\text { Teste de Breusch-Pagan- } \\
\text { Godfrey (BPG) }\end{array}$ & 7,81473 & 7,43856 \\
\hline \multicolumn{2}{c}{ Fonte: Elaborado pelos autores }
\end{tabular}

Por conseguinte, nessa investigação o valor de $\theta$ foi menor que o valor crítico da distribuição de qui-quadrado com três graus de liberdade (pois há quatro regressores), ao nível de significância de 5\%. Nessas circunstâncias, pode-se aceitar a hipótese de homocedasticidade.

\subsubsection{Normalidade dos Resíduos}

Para avaliação da normalidade dos resíduos empregou-se o Teste de KolmogorovSmirnov. Este exame consiste em determinar o valor do coeficiente $D$, que é comparado com os valores da tabela padronizada para valores críticos de estatística $D$, esse fator representa a distância euclidiana máxima entre a função de distribuição empírica acumulada e a teórica que está sendo testada. A Tabela 2 revela os valores obtidos no teste.

Tabela 3 - Teste de Kolmogorov-Smirnov

\begin{tabular}{c|c|c|c}
\hline $\begin{array}{c}\text { TÉCNICA } \\
\text { ESTATístICA } \\
\text { UTILIZADA }\end{array}$ & FóRMULA & $\begin{array}{c}\text { EsTATíSTICA D } \\
\text { TABELADA }\end{array}$ & $\begin{array}{c}\text { ESTATÍSTICA D } \\
\text { CALCULADA }\end{array}$ \\
\hline $\begin{array}{c}\text { Teste de } \\
\text { Kolmogorov- } \\
\text { Smirnov }\end{array}$ & $\begin{array}{l}\text { Onde: } \mathrm{n}=\text { tamáx }\left|(\mathbf{i} / \mathbf{n})^{\mathbf{2}}{ }_{-} \mathbf{Z}_{\mathbf{i}}\right| \\
2,3, \ldots, \mathrm{n} ; \text { e } \mathrm{Z}_{\mathrm{i}}=\text { probabilidade acumulada } \\
\text { da distribuição normal padronizada. }\end{array}$ & 0,1511 & 0,074 \\
\hline
\end{tabular}

Fonte: Elaborado pelos autores

Desta forma, depreende-se que o valor de $D$ calculado é menor que o valor de $D$ crítico, para um nível de significância de 5\%. Então, se aceita a hipótese de que os resíduos se comportam seguindo uma distribuição normal de probabilidades.

\subsubsection{Multicolinearidade}

A multicolinearidade é um fenômeno amostral, pelo qual se verifica a existência de alto grau de correlação entre as variáveis independentes de determinado modelo equacionado. A violação desse pressuposto básico pode ser prejudicial às análises, porquanto, se estas variáveis possuem tal característica, podem prever de forma semelhante o comportamento da 
variável dependente. No modelo proposto neste artigo, utilizou-se a matriz de correlação para esta análise, conforme demonstrada na Tabela 4.

Tabela 4 - Matriz de Correlação das Variáveis Independentes

\begin{tabular}{l|c|c|c|c}
\multicolumn{5}{c}{ Tabela 4 - Matriz de Correlação das Variáveis Independentes } \\
\hline ILG & ILG & RENT & TAEM & EBITDA \\
\hline RENT & 1 & & & \\
\hline TAEM & 0,051 & 1 & & \\
\hline EBITDA & 0,009 & 0,115 & 1 & \\
\hline \multicolumn{6}{c}{ Fonte: Elaborado pelos autores }
\end{tabular}

Depreende-se por meio da análise da Tabela 4 que as variáveis independentes não representam um alto grau de correlação, com exceção das variáveis: tamanho da empresa (TAEM) e EBITDA que têm coeficiente de correlação de 0,637.

\section{RESULTADOS E DISCUSSÕES}

Validadas as suposições básicas do modelo de regressão proposto, esta seção apresenta os resultados obtidos por meio das estatísticas descritivas, dos coeficientes estimados e da análise das hipóteses da pesquisa.

\subsection{ESTATÍSTICAS DESCRITIVAS}

As médias e os desvios-padrão do endividamento (variável dependente) e dos índices de liquidez geral, rentabilidade, tamanho da empresa e EBITDA (variáveis independentes) das empresas selecionadas para análise, são apresentados na Tabela 5.

Tabela 5 - Estatística Descritiva

\begin{tabular}{l|c|c}
\hline \multicolumn{1}{c|}{ VARIÁVEL } & MÉDIA & DESVIO-PADRÃo \\
\hline END & 0,587 & 0,166 \\
\hline ILG & 1,124 & 0,671 \\
\hline RENT & 0,041 & 0,657 \\
\hline TAEM & 6,683 & 0,811 \\
\hline EBITDA & 120,906 & 230,709 \\
\hline
\end{tabular}

Por meio dos dados relacionados na Tabela 5, depreende-se que a média do endividamento das maiores empresas do Sul do Brasil, é de 58,7\%. As estatísticas, também apontam que a média da rentabilidade do patrimônio líquido das firmas analisadas é de 4,1\% e o índice de liquidez geral médio é de 1,124. Pode-se supor que em média as maiores empresas da região Sul do Brasil possuem uma boa capacidade de honrar os compromissos financeiros que assumiram em suas operações. Por fim, as médias assinalam que o EBITDA médio de tais organizações apresenta-se em torno de 121 milhões de dólares de geração de caixa e o tamanho médio das maiores empresas do sul do Brasil é de aproximadamente 6,683, significando que a média de faturamento dessas empresas é de 800 milhões de dólares.

\subsection{COEFICIENTES ESTIMADOS}


A Tabela 6 apresenta o resultado da regressão múltipla obtida, incluindo os coeficientes estimados da equação representativa do modelo, a estatística $t$ e o coeficiente de determinação ajustado $\left(\mathrm{R}^{2}\right)$. Para Corrar, Theóphilo e Bergmann (2004) a estatística $t$ fornece os valores de $t$ teste para análise dos coeficientes e o coeficiente de determinação $\left(\mathrm{R}^{2}\right)$ mede o grau de ajustamento da reta de regressão aos dados observados, indicando o poder explicativo da regressão.

Tabela 6 - Resultado da Regressão Múltipla com todas as Variáveis

\begin{tabular}{|c|c|c|c|c|}
\hline $\begin{array}{c}\text { VARIÁVEL } \\
\text { INDEPENDENTE }\end{array}$ & $\begin{array}{c}\text { COEFICIENTE } \\
\text { ESTIMADO }\end{array}$ & $\begin{array}{c}\text { ESTATÍSTICA } \\
T\end{array}$ & $\begin{array}{c}\mathbf{R}^{2} \\
\text { AJUSTADo }\end{array}$ & EQUAÇÃO DE REGRESSÃO \\
\hline ILG & $-0,1450$ & $-6,389$ & \multirow{4}{*}{0,362} & \multirow{4}{*}{$\begin{array}{c}E N D=0,53405-0,1450 .(I L G)-0,0506 \\
(R E N T)+0,0367 .(\text { TAEM) }-0,0002 . \\
(E B I T D A)\end{array}$} \\
\hline RENT & $-0,0506$ & $-2,221$ & & \\
\hline TAEM & 0,0367 & 1,527 & & \\
\hline EBITDA & $-0,0002$ & $-2,649$ & & \\
\hline
\end{tabular}

Os resultados mostram que as variáveis explicativas do modelo de regressão proposto são o índice de liquidez geral (ILG), a rentabilidade (RENT) e o EBITDA, que se apresentam estatisticamente relevantes. Em contrapartida, a variável denominada tamanho da empresa (TAEM) não é estatisticamente relevante, porém, quando excluída do modelo verifica-se uma diminuição do poder explicativo da regressão como um todo, como mostra a Tabela 7 . Tal fato se explica pela alta correlação existente entre as variáveis TAEM e EBITDA de 63,7\%.

Tabela 7 - Resultado da Regressão Múltipla sem a Variável TAEM

\begin{tabular}{|c|c|c|c|c|}
\hline $\begin{array}{l}\text { VARIÁVEL } \\
\text { INDEPENDENTE }\end{array}$ & $\begin{array}{l}\text { COEFICIENTE } \\
\text { ESTIMADO }\end{array}$ & $\begin{array}{c}\text { ESTATÍSTICA } \\
T\end{array}$ & $\begin{array}{c}\mathbf{R}^{2} \\
\text { AJUSTADO }\end{array}$ & EQUAÇÃO DE REGRESSÃO \\
\hline ILG & $-13,9948$ & $-6,181$ & \multirow{3}{*}{0,351} & \multirow{3}{*}{$\begin{aligned} E N D= & 76,3740-13,9948 .(I L G)-0,0481 \\
& (R E N T)-0,0143 .(E B I T D A)\end{aligned}$} \\
\hline RENT & $-0,0481$ & $-2,099$ & & \\
\hline EBITDA & $-0,0143$ & $-2,158$ & & \\
\hline
\end{tabular}

Apesar do coeficiente de determinação ajustado ter sido de 36,2 \%, indicando que os fatores estudados explicam boa parte do endividamento das empresas analisadas, também sugere que outras variáveis podem ser agrupadas ao modelo para se encontrar um poder explicativo superior a este apresentado no estudo.

\subsection{AVALIAÇÃO DAS HIPÓTESES DA PESQUISA}

A partir das análises realizadas no item anterior, pode-se avaliar a relação existente entre o endividamento (variável dependente) e os potenciais fatores determinantes desse endividamento (variáveis independentes). Destarte, retorna-se às hipóteses propostas para se comparar as relações esperadas por meio da exposição teórica levantada e as relações observadas no presente estudo. Na Tabela 8 encontra-se o resumo das relações esperadas e das relações efetivamente encontradas das hipóteses propostas. O termo "NS" indica que não existe relação estatística significativa.

Tabela 8 - Avaliação das Hipóteses levantadas

\begin{tabular}{c|c|c}
\hline $\begin{array}{c}\text { FATOR DETERMINANTE } \\
\text { DO ENDIVIDAMENTO }\end{array}$ & RELAÇÃO & RELAÇÃO \\
ESPERADA & OBSERVADA \\
\hline
\end{tabular}




\begin{tabular}{l|c|c}
\hline $\begin{array}{l}\text { FATOR DETERMINANTE } \\
\text { DO ENDIVIDAMENTO }\end{array}$ & $\begin{array}{c}\text { RELAÇÃo } \\
\text { ESPERADA }\end{array}$ & $\begin{array}{c}\text { RELAÇÃo } \\
\text { OBSERVADA }\end{array}$ \\
\hline ILG & negativa & negativa \\
\hline RENT & negativa & negativa \\
\hline TAEM & positiva & NS \\
\hline EBITDA & positiva & negativa \\
\hline
\end{tabular}

Fonte: Elaborado pelos autores

Primeiramente, verifica-se que quanto maior o endividamento, menor é o índice de liquidez geral das empresas selecionadas para análise, confirmando a hipótese 1 de que existe uma relação negativa entre estas variáveis. Tal fato ocorre porque o ILG refere-se à capacidade que estas empresas possuem de honrar com suas dívidas de curto e longo prazo e, quanto maior a utilização de capital de terceiros para esse fim, mais as empresas ficam dependentes de lucros futuros, renegociações de dívidas e vendas de ativo.

A rentabilidade apresenta-se significativa e negativa conforme a hipótese 2 . Sugerindo, em linha com a teoria do Pecking Order, que as empresas brasileiras da Região Sul com maior crescimento tendem a captar menos recursos de terceiros, optando pela utilização dos recursos gerados internamente por meio da geração e retenção dos lucros. Em contrapartida, o tamanho da empresa mostra-se pouco relevante na estrutura de capital das empresas, ou seja, os resultados não confirmaram a teoria dos custos de falência, indicando que as maiores empresas são mais endividadas, conforme propõe a hipótese 3.

Por fim, verifica-se uma relação inversa entre o EBITDA e o endividamento das empresas analisadas, não se confirmando a hipótese 4 de que as empresas com retornos mais elevados e com maior capacidade de geração de caixa podem suportar um endividamento muito alto com relação ao seu valor de mercado. Isso se deve, possivelmente, ao fato de que as empresas, segundo a teoria do Pecking Order, preferem utilizar os recursos gerados internamente a recorrer ao capital de terceiros para financiamento de suas atividades fins.

\section{CONSIDERAÇÕES FINAIS}

A presente pesquisa propôs-se a analisar os fatores que são possíveis determinantes da estrutura de capital das maiores empresas do Sul do Brasil. Ressalta-se que os resultados expostos necessitam ser analisados com bastante prudência, sem generalizações, pois são verificados para a amostra composta por 81 das 100 maiores empresas do Sul do Brasil, categorizadas dessa forma, pela Revista Exame sob o critério de receitas auferidas.

Os resultados obtidos indicaram que os fatores índice de liquidez geral, rentabilidade e EBITDA são fatores relevantes que influenciam o grau de endividamento das organizações em questão, enquanto o tamanho da empresa não teve significância estatística suficiente. Porém, destaca-se que mais fatores devem ser incluídos no modelo proposto, em estudos futuros, para uma maior abrangência de fatores determinantes na estrutura de capital, tais como: risco corporativo, composição de ativos, crescimento de vendas, tipo de capital (empresas de capital aberto ou fechado), controle acionário, etc. Também são importantes estudos longitudinais que abarquem um maior período de tempo, para se prever tendências futuras.

A implicação desse estudo em nível acadêmico é a contribuição para a discussão acerca das teorias de estrutura de capital e alguns fatores determinantes da estrutura de capitais pouco estudados ainda (índice de liquidez geral e EBITDA). Também, esse estudo traz implicações profissionais, principalmente para executivos, na medida em que os auxilia no conhecimento da estrutura de capitais e das teorias financeiras que embasam a tomada de decisões com relação às decisões de investimento, financiamento e dividendos. 


\section{REFERÊNCIAS}

ASSAF NETO, Alexandre. Estrutura e Análise de Balanços - Um Enfoque EconômicoFinanceiro. 8 ed. São Paulo: Atlas, 2006.

BRADLEY, Michael; JARRELL, Gregg A.; KIM, E. Han. On the Existence of an Optimal Capital Structure: Theory and Evidence. The Journal of Finance. v. 39, n. 3, p. 857 - 878, Jul 1984.

BRITO, Giovani A. S.; CORRAR, Luiz J.; BATISTELLA, Flávio D. Fatores Determinantes da Estrutura de Capital das Maiores Empresas que Atuam no Brasil. Revista Contabilidade \& Finanças - USP. São Paulo, n. 43, p. 9 - 19, Jan./Abr. 2007.

COOPER, Donald R.; SCHINDLER, Pamela S. Métodos de Pesquisa em Administração. 7.ed. Porto Alegre: Bookman, 2003.

CORRAR, Luiz J.; THEÓPHILO, Carlos Renato; BERGMANN, Daniel Reed. Regressões. In: CORRAR, Luiz J.; THEÓPHILO, Carlos Renato. Pesquisa Operacional para decisão em Contabilidade e Administração - Contabilometria. São Paulo: Atlas, 2004, p. 75 - 150.

CRUZ, Ana Paula C. da; MENDES, Roselaine da C.; ESPEJO, Márcia M. S. Bortolocci; DAMEDA, André das Neves. Alavancagem Financeira e Rentabilidade: Uma Discussão sobre o Comportamento de empresas do Sul do Brasil à Luz das Teorias Financeiras. In: $18^{\circ}$ Congresso Brasileiro de Contabilidade, Gramado, 2008.

DAMODARAN, Aswath. Finanças Corporativas Aplicadas. Porto Alegre: Bookman, 2002.

DURAND, David. Cost of debt and equity funds for business: trends and problems of measurement. In: Conference on Research on Business Finance. New York: National Bureau of Economic Research, 1952. Disponível em $<$ http://www.nber.org/chapters/c4790.pdf $>$. Acesso em 19.01.2009.

FAMÁ, Rubens; BARROS, Lucas Ayres B. de C.; SILVEIRA, Alexandre Di Miceli da. A Estrutura de Capital é Relevante? Novas Evidências a partir de dados norte-americanos e latino-americanos. Caderno de Pesquisas em Administração. São Paulo: v. 8, n. 2, p. 71-84, Abr./Jun. 2001.

FERRI, Michael G.; JONES, Wesley H. Determinants of Financial Structure: A New Methodological Approach. The Journal of Finance. v. 34, n. 3, p. 631 - 644, Jun 1979.

GUJARATI, Damodar N. Econometria Básica. 4 ed. Rio de Janeiro: Elsevier, 2006.

HAIR JR, Joseph F.; ANDERSON, Rolph E.; TATHAM, Ronald L.; BLACK, William C. Análise Multivariada de Dados. 5. ed. Porto Alegre: Bookman, 2005.

JENSEN, Michael C.; MECKLING, William H. Theory of the Firm: Managerial Behavior, Agency Costs and Ownership Structure. Journal of Financial Economics. v. 3, n. 4, p. 305 360, Out 1976. 
MILLER, Merton H. Debt and Taxes. The Journal of Finance. v. 32, n. 2, p. 261 - 275, Mai 1977.

MODIGLIANI, Franco; MILLER, Merton H. The Cost of Capital, Corporation Finance and the Theory of Investment. American Economic Review. v. 48, n. 3, p. 261-297. Jun. 1958.

MYERS, Stewart C. The Capital Structure Puzzle. Journal of Finance. Chicago: American Finance Association, v. 39, n. 3, Jul. 1984.

MYERS, Stewart C; MAJLUF, Nicholas S. Corporate financing and investment decisions when firms have information that investors do not have. Journal of Financial Economics. v. 13, n. 2, p. $187-221$, Jun 1984.

NAKAMURA, Wilson T.; MARTIN, Diógenes M. L.; FORTE, Denis; CARVALHO FILHO, Antonio F.; COSTA, André C. F. da; AMARAL, Alexandre C. do. Determinantes de Estrutura de Capital no Mercado Brasileiro - Análise de Regressão com Painel de Dados no Período 1999 - 2003. Revista Contabilidade \& Finanças - USP. São Paulo, n. 44, p. 72 85, Mai./Ago. 2007.

RAJAN, Raghuram G.; ZINGALES, Luigi. What Do We Know about Capital Structure? Some Evidence from International Data. The Journal of Finance. v. 50, n. 5, p. 1421 - 1460, Dec 1995.

ROSS, Stephen A; WESTERFIELD, Randolph W; JAFFE, Jeffrey F. Administração Financeira. $2^{a}$ ed. São Paulo: Atlas, 2007.

SANTOS, Carolina Macagnani dos. Levantamento dos Fatores Determinantes da Estrutura de Capital das Empresas Brasileiras. São Paulo, 2006. Dissertação (Mestrado em Administração de Empresas) - Faculdade de Economia, Administração e Contabilidade, Universidade de São Paulo - Ribeirão Preto.

SOUZA, Mateus Clovis de; FUNCHAL, Bruno; BAPTISTA, Ézio. Nova Lei de Falências: Efeitos na Estrutura de Capital das Empresas Brasileiras. In: IAAER - ANPCONT $3 r d$, International Accounting Congress, São Paulo, 2009.

TITMAN, Sheridan; WESSELS, Roberto. The Determinants of Capital Structure Choice. The Journal of Finance. v. 43, n. 1, p. 1 - 19, Mar 1988.

TOY, Norman; STONEHILL, Arthur; REMMERS, Lee; WRIGHT, Richard; BEEKHUISEN, Theo. A Comparative International Study of Growth, Profitability, and Risk as Determinants of Corporate Debt Ratios in the Manufacturing Sector. The Journal of Financial and Quantitative Analysis. v. 9, n. 5, p. 875 - 886, Nov 1974. 